Abstract CPC-122 Table 1

\begin{tabular}{|c|c|c|c|c|c|}
\hline Risk factors & Patients & CR (N, \%) & Non-CR (N, \%) & $\begin{array}{l}\text { Risk reduction } \\
\text { CR vs. Non-CR }\end{array}$ & $\begin{array}{l}\text { Statistical difference (SD) or Non-significant } \\
\text { difference (NSD) }\end{array}$ \\
\hline $\begin{array}{l}\text { Age }(n=30) \\
\text { Age }>75 \\
\text { Age } 51-74 \\
\text { Age } 31-50\end{array}$ & $\begin{array}{l}3 \\
21 \\
6\end{array}$ & $\begin{array}{l}3(100 \%) \\
16(76.2 \%) \\
2(33.3 \%)\end{array}$ & $\begin{array}{l}0 \\
5(23.8 \%) \\
4(66.7 \%)\end{array}$ & $\begin{array}{l}100 \% \\
52.4 \% \\
33.3 \%\end{array}$ & SD between all subgroups. \\
\hline $\begin{array}{l}\text { Sex }(n=30) \\
\text { Female } \\
\text { Male }\end{array}$ & $\begin{array}{l}14 \\
16\end{array}$ & $\begin{array}{l}8(57.1 \%) \\
13(81.2 \%)\end{array}$ & $\begin{array}{l}6(42.9 \%) \\
3(18.8 \%)\end{array}$ & $\begin{array}{l}14.2 \% \\
62.4 \%\end{array}$ & NSD \\
\hline History of motion sickness & 4 & $3(75 \%)$ & $1(25 \%)$ & $50 \%$ & \\
\hline Pregnancy-induced vomiting & 4 & $3(75 \%)$ & $1(25 \%)$ & $50 \%$ & \\
\hline Radiotherapy & 3 & $2(66.7 \%)$ & $1(33.3 \%)$ & $33.3 \%$ & \\
\hline Anxiety/depression & 6 & $3(50 \%)$ & $3(50 \%)$ & - & \\
\hline $\begin{array}{l}\text { Alcohol intake history }(n=30) \\
\text { None } \\
\text { Mild }(1-5) \\
\text { Moderate }(6-14) \\
\text { High }(>14)\end{array}$ & $\begin{array}{l}19 \\
9 \\
1 \\
1\end{array}$ & $\begin{array}{l}12(63.2 \%) \\
6(66.7 \%) \\
1(100 \%) \\
1(100 \%)\end{array}$ & $\begin{array}{l}7(36.8 \%) \\
3(33.3 \%) \\
0 \\
0\end{array}$ & $\begin{array}{l}26.4 \% \\
33.4 \% \\
100 \% \\
100 \%\end{array}$ & $\begin{array}{l}\text { SD between zero and mild consumption vs. } \\
\text { moderate and high. }\end{array}$ \\
\hline
\end{tabular}

CINV was investigated. CR was defined as no emetic episodes during the overall 5-day study period. Patients' risk factors were recorded before chemotherapy infusion. All patients received intravenous 5HT3-receptor antagonists before chemotherapy infusion and a two-drug combination (metoclopramide and dexamethasone) on the following four days. Patients kept a diary to report CINV during the 5-day period. Univariate analyses were performed to determine the risk factors significantly associated with emesis after the first cycle of chemotherapy. Risk reduction between CR and non-CR results were calculated. The statistical significance among risk-factor subgroups was also evaluated in order to assess the extent of influence of each one.

Results A total of 30 patients were evaluated. The incidence of emesis is summarised in the table.

Conclusions The younger the patient the less emetic control there was. Although the risk was higher in women, this difference was not significant. None or minor consumption of alcohol had significantly higher risk of emesis than moderate or high. A multivariable analysis may be performed to confirm the relationship between risk factors and CINV.

No conflict of interest.

\section{CPC-123 RISPERIDONE AND SUSPECTED ANGIONEUROTIC OEDEMA: CONTRIBUTION OF MULTIDISCIPLINARY CARE}

doi:10.1136/ejhpharm-2013-000276.580

${ }^{1} \mathrm{M}$ Agullo, ${ }^{2} \mathrm{~S}$ Duffy, ${ }^{3} \mathrm{~A}$ Du Thanh, ${ }^{1} \mathrm{M}$ Villiet, ${ }^{1} \mathrm{~S}$ Hansel Esteller. ${ }^{1} \mathrm{CHRU}$ of Montpellier Lapeyronie Hospital, Pharmacy, Montpellier, France; ${ }^{2} \mathrm{CHRU}$ of Montpellier Lapeyronie Hospital, Emergencies, Montpellier, France; ${ }^{3} \mathrm{CHRU}$ of Montpellier Saint Eloi Hospital, Dermatology Regional Reference Center for Bradykinin Angioedema, Montpellier, France

Background Psychotropic drugs may cause cutaneous eruptions with various degrees of severity ranging from urticaria to 'angioedema' (AE). Respiratory tract obstruction needs emergency care.

Purpose To report on a patient who developed facial AE following treatment with risperidone.

Materials and Methods An 85-year-old woman was admitted to the emergency department (ED) for acute respiratory failure 24 hours after risperidone was introduced.

Results She presented macroglossia, dyspnoea and oedema of the soft palate, unresolved with antihistamines and steroids. In the ED, risperidone was reintroduced for agitation. It was immediately followed by severe dyspnoea, oedema of the tongue and uvula requiring admission to the intensive care unit. Risperidone imputability was suspected after a review of the literature. The Regional Reference Centre for Bradykinin AE (BAE) was consulted. Allergic oedema caused by risperidone but not BAE was concluded (delay of occurrence, absence of real BAE case with risperidone). Risperidone was stopped, the patient was monitored and treated with the optimal dose of steroids and antihistamines. Oedema resolved in 48 hours and patient went back home without sequelae. Naranjo evaluation scored 9 , so it was highly probable that oedema was linked to the drug.

Conclusions AE can result in laryngeal oedema and fatal airway obstruction. When differential diagnoses are eliminated, AE is classified into allergic/pseudo-allergic or bradykinin-related (hereditary or acquired with angiotensin-converting enzyme inhibitors and sartans). The mechanism of drug-induced BAE seems to be mediated by increased plasma bradykinin levels, because these drugs reduce its breakdown.

$\mathrm{AE}$ has been reported to occur with antipsychotics like risperidone, but these drugs probably produce histaminergic AE, not BAE. In our case, this hypothesis must be ruled out with cutaneous allergology prick tests with risperidone.

Diagnosis of BAE can be difficult. Clinical signs and oedema resistant to conventional treatments have led to suspicion of BAE. French Reference Centres can improve and optimise detection and treatment of these orphan diseases and limit use of expensive drugs (e.g. icatibant: 6,300 US dollars per patient).

No conflict of interest.

\section{CPC-124 RIVAROXABAN OR CONVENTIONAL THROMBOPROPHYLAXIS AFTER MAJOR ORTHOPAEDIC SURGERY IN ROUTINE PRACTISE: INFLUENCE OF CO- MEDICATIONS ON OUTCOMES IN THE XAMOS STUDY}

doi:10.1136/ejhpharm-2013-000276.581

${ }^{1} \mathrm{R}$ Kreutz, ${ }^{2} \mathrm{~S}$ Haas, ${ }^{3} \mathrm{G}$ Holberg, ${ }^{4} \mathrm{MR}$ Lassen, ${ }^{5} \mathrm{LG}$ Mantovani, ${ }^{3} \mathrm{~A}$ Schmidt, ${ }^{6} \mathrm{AGG}$ Turpie. ${ }^{1}$ Charité, Department of Clinical Pharmacology and Toxicology, Berlin, Germany; 2Institute for Experimental Oncology and Therapy Research, Technical University of Munich, Munich, Germany; ${ }^{3}$ Bayer Healthcare AG, GMA, Berlin, Germany; ${ }^{4}$ Glostrup Hospital University of Copenhagen, Clinical Trial Unit, Copenhagen, Denmark; ${ }^{5}$ Federico II University of Naples, CIRFF Center of Pharmacoeconomics, Naples, Italy; ${ }^{6} \mathrm{Hamilton}$ Health Services, Department of Medicine, Hamilton Ontario, Canada

Background Rivaroxaban, a direct Factor Xa inhibitor, has been shown to be more effective in preventing venous thromboembolism than enoxaparin regimens, with a similar safety profile, in patients undergoing hip or knee arthroplasty (the phase III RECORD studies). Rivaroxaban is approved for this indication worldwide.

Purpose To examine the effectiveness and safety of rivaroxaban for thromboprophylaxis in routine clinical practise and the impact of selected co-medication use on outcomes. 